\title{
Regenerative Role of l-Lysine Amino Acid on Alimentary Canal of Fresh Water Food Fish Due to Chronic Chromium Toxicity- A Lab Study
}

\section{Balveer Singh Dhami*}

Department of Zoology, Bareilly College, Bareilly, Utter Pradesh, India

*Corresponding Author: Balveer Singh Dhami, Department of Zoology, Bareilly

College, Bareilly, Utter Pradesh, India.
Received: December 28, 2021

Published: January 31, 2022

(C) All rights are reserved by Balveer Singh

Dhami.

\section{Abstract}

The present study was carried out to investigate the preventive role of L-Lysine amino acid in chronic chromium toxicity on alimentary canal of freshwater food fish, Clarias batrachus. The trivalent and hexavalent forms of chromium are important for human health and other organisms. Chromium maintains normal glucose tolerance factor. The deficiency of chromium leads atherosclerosis in rabbits and also effects reproduction, life spawn and growth. Moreover, the deficiency of chromium leads anxiety, mental retardation, vision impairment, poor immunity, hypoglycemia and unhealthy level of cholesterol. Toxicity of chromium on liver, stomach and kidney is worked out by many workers in mammals and fish. Chromium is one of the pollutants in urban sewage. It is used in tannery, paints, steel, textiles, printing, electroplating, rubber industries, pigments, plating, fungicides, corrosion inhibitors etc. L-Lysine amino acid is an essential amino acid and used as nutritional supplements. It is essential for growth and calcium absorption from intestine. Lysine also used to prevent osteoporosis, and it is also important for collagen synthesis, hormone and antibody production. To investigate the preventive role of L-lysine in chromium toxicity, the fish was exposed to $300 \mathrm{ppm}$ chromic chloride $\left(\mathrm{T}_{2}\right)$ for thirty days along with control $\left(\mathrm{T}_{1}\right)$. during this period, the histopathology of stomach and intestine show atrophy of gastric epithelium, reduced mucosal folds and degeneration of gastric glands. The studies with Transmission Electron Microscopy of stomach of control $\left(\mathrm{T}_{1}\right)$ and treated fish $\left(\mathrm{T}_{2}\right.$ and $\left.\mathrm{T}_{3}\right)$ were conducted. TEM shows damaged E.R., reduced parietal cells along with reduction in the number of zymogen granules. In intestine, it shows atrophy of epithelium, reduced size and fusion of villi and necrosis also observed. In the combination dose experiment $\left(\mathrm{T}_{3}\right.$ ), the fish was given an injection of L-Lysine amino acid @ $0.4 \mathrm{mg} / 100$ gm body weight per day for thirty days. During this study, an improvement was observed after thirty days treatment, and it shows the nearly normal size of mucosal folds, epithelium of gastric mucosa regenerated as normal. In combination dose $\left(\mathrm{T}_{3}\right)$, after thirty days of exposure, embedding of villi, villous atrophy and villous fusion is not seen. Intestinal glands as well as intestinal mucosa were observed nearly normal. keywords: Lysine; Trivalent Chromium; Clarias; Atrophy; TEM; Villi

\section{Introduction}

Toxic metals are widely found in aquatic environments, due to disposal of agricultural, industrial and urban wastes generated by human activities [1]. These compounds have been found to be very toxic, genotoxic, mutagenic and carcinogenic [2]. Among them, water pollution due to chromium $(\mathrm{Cr})$ is regarded as one of the main and most severe environmental problems [3].
Chromium is most abundant element in the Earth's crust predominately in trivalent form. Both, trivalent and hexavalent forms of chromium are important for human health and other organisms, however, hexavalent chromium does not occur naturally in the environment and produced anthropogenically. In biological system, the oxidation of trivalent chromium to hexavalent chromium never occurs and in food stuffs, it presents in trivalent form. Normal level of chromium maintains glucose tolerance factor [4]. The deficiency

Citation: Balveer Singh Dhami. "Regenerative Role of l-Lysine Amino Acid on Alimentary Canal of Fresh Water Food Fish Due to Chronic Chromium Toxicity- A Lab Study". Acta Scientific Veterinary Sciences 4.2 (2022): 75-80. 
of chromium in rabbits leads to atherosclerosis [5,6]. The chromium deficiency also effects reproduction, life spawn and growth [7].

Long-term exposure to hexavalent chromium exhibited several alterations in behaviour, physiology, cytology, histology and morphology in freshwater fishes [8,9]. Organ distribution of several chromium salts following intravenous injection was also reported in rats [10]. Generally, $\mathrm{CrCl}_{3}$ is concentrated in liver, spleen and bone-marrow, and once deposited, it cleared slowly. The gastric toxicity of chromium in mammals and other organisms has been described by previous workers $[11,12]$. The toxic effects of chromium and other heavy metals on intestine and other organs of freshwater fishes have been worked out by different workers $[8,13]$. Hexavalent form is much toxic as compared to the trivalent form, however not much work has so far been done on chronic toxicity of chromium on alimentary canal of animals [8].

Because of the hazardous effects of chromium, several studies were designed to find out protective agents. Amino acid therapy in the treatment of experimental acute renal failure in rats is worked out [14]. The effect of a keto acid plus essential amino acid supplement to a restricted diet on the progression of chronic renal failure was also studied $[15,16]$. It was also reported that amino acid therapy could be used for the treatment of alcoholic hepatitis and cirrhosis [17]. Protective role of amino acids in hepatic coma was also described [18]. The role of branched-chained amino acids in hepatic encephalopathy was established [19]. Some aspects of amino acid therapy in the treatment of acute and chronic renal diseases have been worked by previous workers $[20,21]$.

On reviewing the literature, it appears that studies on regenerative effects with the treatment of essential amino acids are very scanty $[16,20,22,23]$. Therefore, the present study aimed to evaluate the toxic effects of chromium in Clarias batrachus and amelioration as well as antagonizing this toxic effect by using L-lysine amino acid.

\section{Material and Methods}

For the present study healthy, live freshwater food fish Clarias batrachus (Linn.) were obtained from local freshwater fishpond located at Hastinapur, Meerut $\left(29.17^{\circ} \mathrm{N} 78.02^{\circ} \mathrm{E}\right)$ for experimentation. The fishes of nearly same size and weight (about $100 \mathrm{gm}$ ) were selected for experiment. Animals acclimatized in glass aquaria for 10 days at Department of Zoology, Meerut college, Meerut, before starting the experiment and fed with commercial fish food twice a day. The animals were divided into three groups. First group of control $\left(\mathrm{T}_{1}\right)$ and the second $\left(\mathrm{T}_{2}\right)$ and third group $\left(\mathrm{T}_{3}\right)$ of experimental animals, in which, each group was consisted of 10 fishes, kept in three separate glass aquaria. Control fishes $\left(\mathrm{T}_{1}\right)$ were given commercial food throughout the experimental period. Second experimental group $\left(\mathrm{T}_{2}\right)$ was exposed to $300 \mathrm{ppm}$ of chromic chloride for 30 days, to study the chronic toxicity of trivalent chromium, while in another experimental group $\left(\mathrm{T}_{3}\right)$, combination dose of L-Lysine amino acid along with 300 ppm of chromic chloride was given as intramuscular injection of $0.4 \mathrm{mg} / 100$ gm body weight/day for 30 days. After 30 days of chronic exposure, stomach and intestine were dissected out and fixed in alcoholic Bouin's fixative for histopathological findings. The tissues of control fish were also fixed separately to compare the toxicity of chromium. Sections of seven micron were cut in rotator microtome and observed under microscope. Staining of tissues carried out in Delafield's haematoxylin and alcoholic eosin.

The Transmission Electron Microscopic studies of stomach of the control and experimental animals were carried out at AIIMS, New Delhi. For this, the stomach of control fish and of experimental groups dissected out and fixed in Osmium tetroxide $\left(\mathrm{OsO}_{4}\right)$ separately. These samples were transported to AIIMS for TEM study, after keeping them in ice packs.

\section{Results and Discussion}

The present study shows that chronic exposure to trivalent chromium is toxic to stomach and intestine of freshwater food fish Clarias batrachus. The toxic effect of trivalent chromium has not yet been ample demonstrated in experimental animals. However according to previous study, the trivalent chromium even in large doses failed to induce any harmful effects [24]. At the same time, it has been shown that the hexavalent chromium immediately converted into trivalent form after the penetration of cell membrane in tissues [25]. The hexavalent form is more toxic than the trivalent form. The oral administration of hexavalent chromium is partly reduced to trivalent form by acidic medium of gastric juice [26]. Hence it is possible that the actual effect displayed may be due to the trivalent form as amply demonstrated in our studies also. The toxicity of hexavalent chromium is widely worked out in animals and human being but the toxicity of trivalent chromium is still to work in both animals and human. In the present study it is found 
that trivalent chromium is highly toxic to the gastric mucosa, intestinal epithelium and villi.

Our findings revealed that after chronic exposure to trivalent chromium, there is marked reduction or nearly absence in mucosal folds and where present, they become atrophied. Degeneration of gastric glands also observed. Peptic ulcers were reported in industrial workers exposed to chromium [12], however ulceration in stomach has not been observed during present investigations in a teleost fish. Necrotic patches added further evidence of degenerative changes in the gastric mucosa (Figure 1).

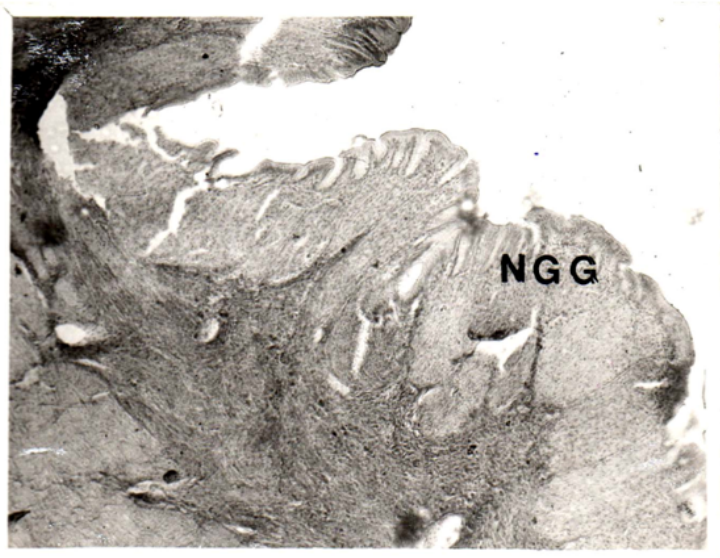

Figure 1: T.S. Stomach Showing reduced mucosal folds and necrosed gastric glands after chronic exposure (T2) × 400 (NGG - Necrosed Gastric Gland).

The other layers of stomach did not display much changes. Several other workers, experimenting with heavy metals are also reported similar findings. Some workers reported toxic effects of chromium on gastro-intestinal tract, they found gastritis, oedema, hyperemia, erosion of mucosa and polyposis [11,27].

Study of stomach with Transmission Electron Microscope of the control and treated fish carried out during the experiments. The stomach of control fish $\left(\mathrm{T}_{1}\right)$ shows normal endoplasmic reticulum, large number of mucus cells, oxyntic cells and zymogen cell with granules, all these indicate normal gastric activity [22] (Figure 2).

The Transmission Electron Microscopic study of stomach of treated fish, exposed to thirty days to chromium $\left(\mathrm{T}_{2}\right)$, showed

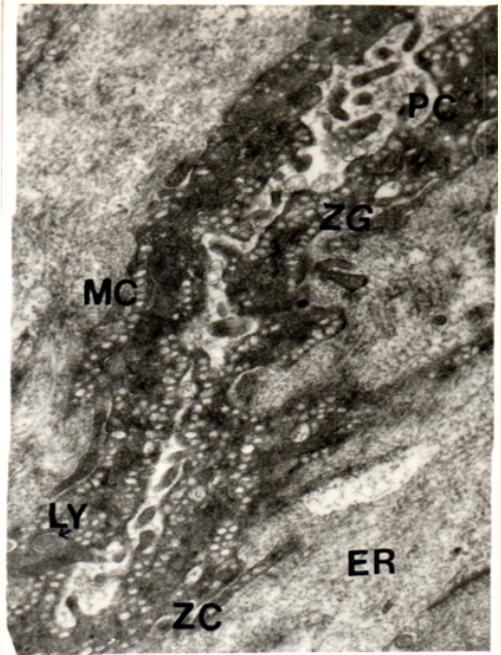

Figure 2: Electron microphotograph Showing gastric glands in control fish (T1) $\times 4600$.

MC: Mucus Cells, PC: Parietal Cells, ZG: Zymogen Granules, ER: Endoplasmic Reticulum, LY: Lysosomes, ZC: Zymogen Cells.

degenerated gastric glands, damaged Endoplasmic Reticulum, reduced number of secretory vesicles. The other histopathological changes observed in stomach are reduced number of parietal cells, zymogen granules and glandular dystrophy is well marked. All these subcellular changes in stomach indicate that chromium is highly toxic to gastric glands [28,29] (Figure 3).

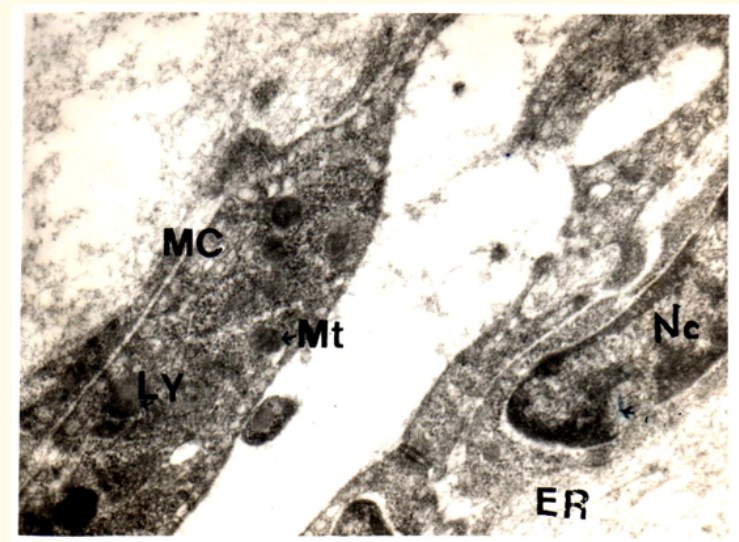

Figure 3: Electron microphotograph Showing necrosed gastric after Chronic exposure (T2) $\times 6300$.

MC: Mucus Cells, ER: Endoplasmic Reticulum, LY: Lysosomes, MT: Mitochondria, Nc: Nucleus. 
During present investigation, chronic chromium toxicity also observed on intestine of $C$. batrachus, which shows erosion and atrophy of the villi, reduced size of villi with villous fusion and villous invading. Liquefactive necrosis of musculature is also observed. Due to chromium toxicity, lysis of the intestinal epithelium in fish was also described [30] (Figure 4 and 5).
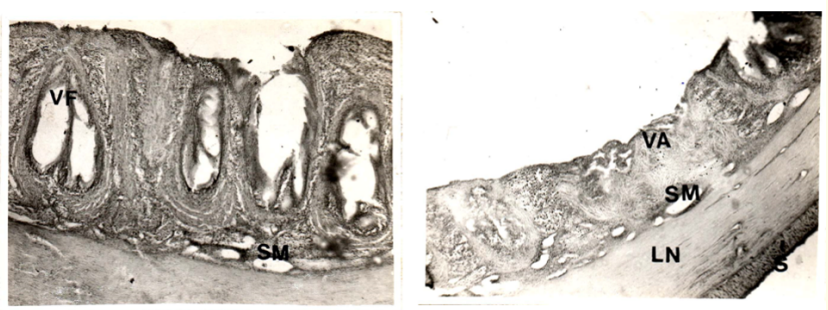

Figure 4 and 5: T.S. of Intestine Showing villous fusion, villous atrophy and embedding after Chronic exposure (T2) $\times 100$.

VF: Villous Fusion, SM: Sub Mucosa, VA: Villous Atrophy, LN: Liquefactive Necrosis, S: Serosa.

The mixture of essential amino acids and keto acids used by many workers to treat last-stage kidney failure patients $[15,16,31]$. All these workers never used such nutritional supplements in heavy metals toxicity. Earlier workers reported that amino acid therapy could be used for the treatment of alcoholic hepatitis and cirrhosis [17]. The protective role of branched chain amino acids in hepatic coma was also described [18]. The role of branched chain amino acids was evaluated in hepatic encephalopathy and liver cirrhosis [32]. Intravenous amino acid therapy was used for kidney function in critically ill patients [33]. Some literature is available on the use of L-glutamine amino acid to heal the gut lining.

The toxicity of amino acids is not much worked out except few references available on the toxicity of few amino acids on kidney [34,35]. Nephrotoxicity and hepatotoxicity of acute high dose of Llysine amino acid in freshwater food fish was also worked out [36].

In the present study the L-lysine amino acid is used to treat the toxicity of chromium on stomach and intestine in a food fish. It is observed that in combination dose $\left(\mathrm{T}_{3}\right)$, the damage to the gastric epithelium, gastric glands, size of mucosal folds gradually show improvement and after thirty days become nearly normal, this indicates that L-lysine has regenerative effect in stomach after chronic chromium exposure. This is further confirmed by Electron Microscopic observations which show normal gastric glands, multiplication of mitochondria in gastric mucosa, thereby indicating regenerative changes (Figure 6 and 7).
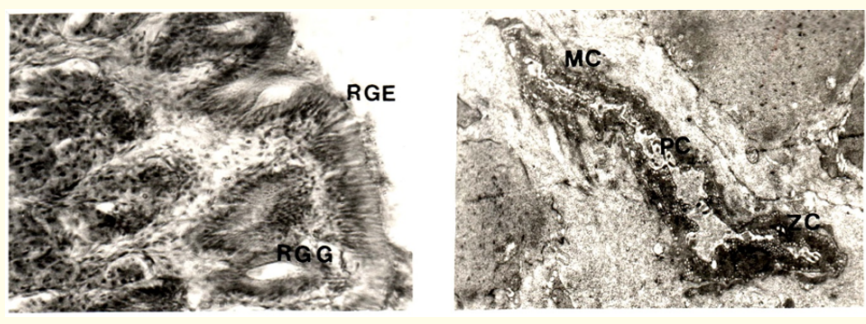

Figure 6 and 7: T.S. Stomach Showing Regenerating Epithelium and Gastric Gland after combination dose (T3) $\times 400$.

RGG: Regenerating Gastric Glands, RGE: Regenerating Gastric Epithelium, MC: Mucus Cells, PC: Parietal Cells, ZG: Zymogen

Granules.

After thirty days chronic exposure with combination dose of Llysine amino acid, the intestine does not show invading of the villi, villous atrophy and villous fusion. The architecture of epithelium covering intestinal villi, intestinal glands and intestinal mucosa become completely normal [22,23] (Figure 8 and 9).
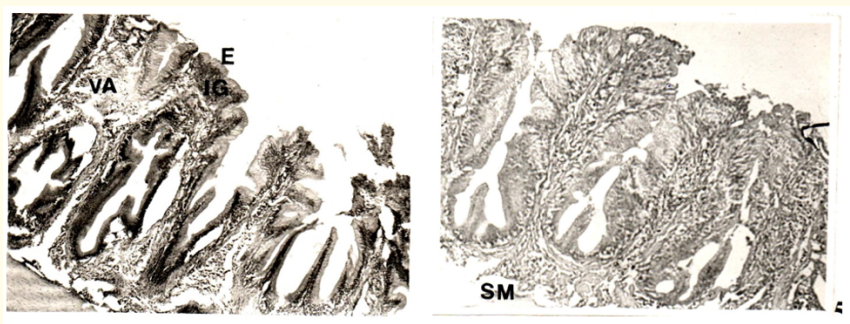

Figure 8 and 9: T.S. Intestine Showing normal architecture of intestine with normal Epithelium, Intestinal Gland, Serosa after combination dose (T3) $\times 100$.

E: Epithelium, IG: Intestinal Gland, VA: Villous Atrophy, SM: Sub Mucosa, S: Serosa.

The present findings show that the use of essential amino acids assume greater importance in view of the increasing pollution of water, air and soil with heavy metals toxicity in different physical forms. In our study, it is observed that L-lysine amino acid can play 
a protective role in the metal toxicity with a balanced dose because high doses can induce damage to the vital organs like kidney and liver [36].

\section{Conclusion}

In the present study all these findings throw light on the therapeutic use of essential amino acids as a new concept to prevent heavy metals toxicity in animals and human being. The use of Llysine amino acid in chromium toxicity on stomach and intestine of fish opens a wide discussion in the area of toxicity due to heavy metals.

\section{Bibliography}

1. Ahmad I., et al. "Oxidative stress and genotoxic effects in gill and kidney of Anguilla anguilla L. exposed to chromium with or without pre-exposure to ß-naphthoflavone". Mutation Research - Genetic Toxicology and Environmental Mutagenesis 608 (2006): 16-28.

2. Kumar P., et al. "Genotoxic and mutagenic assessment of hexavalent chromium in fish following in-vivo chronic exposure". Human and Ecological Risk Assessment: An International Journal 18 (2012): 855-870.

3. Garai P., et al. "Effect of heavy metals on fishes: Toxicity and Bioaccumulation". Journal of Clinical Toxicology S18 (2021): 001.

4. Mertz W and Schwarz K. "Relation of glucose tolerance factor to impaired glucose tolerance in rats on stock diets". American Journal of Physiology 196 (1959): 614-618.

5. Novakova S., et al. "Content of hexavalent chromium in water supplies and its effect on the development of experimental atherosclerosis in warm blooded animals". Gigiena i sanitariia 5 (1974): 78-80.

6. Abraham AS., et al. "The effect of chromium on established atherosclerotic plaques in rabbits". The American Journal of Clinical Nutrition 33 (1980): 2294-2298.

7. Schroeder HA., et al. "Chromium, cadmium and lead in rats: effects on life span, tumors and tissue levels". Journal of Nutrition 83 (1965): 239-250.

8. Bakshi A and Panigrahi AK. "A comprehensive review on chromium induced alterations in fresh water fishes". Toxicology Reports 5 (2018): 440-447.
9. Yu Z., et al. "Toxic effects of hexavalent chromium on bioaccumulation, appoprosis, oxidative damage and inflammatory response in Channa asiatica". Environmental Toxicology and Pharmacology 87 (2021):103725.

10. Visek WJ., et al. "Metabolism of chromium by animals as influenced by chemical state". Proceedings of the Society for Experimental Biology and Medicine 84 (1963): 610-613.

11. Sterikhova NP., et al. "Gastric pathology in workers engaged in production of chromium salts". Gigiena truda i professional'nye zabolevaniia 3 (1978): 19-23.

12. Satoh K., et al. "Epidemiological study of workers engaged in the manufacture of chromium compounds". Journal of Occupational and Environmental Medicine 23 (1981): 835-838.

13. Panigrahi AK., et al. "A comprehensive review on the uptake by and accumulation of some heavy metals in freshwater fishes" 5 (2021): 440-447.

14. Oken DE., et al. "Amino acid therapy in the treatment of acute renal failure in the rat". Kidney International 17 (1980): 14.

15. Mitch WE., et al. "The effect of a keto acid-amino acid supplementation to a restricted diet on the progression of chronic renal failure". The New England Journal of Medicine 311.10 (1984): 623-629.

16. Walser M., et al. "Progression of chronic renal failure in patient given keto acids following amino acids". Kidney International 32 (1987): 123-128.

17. Nasrallah SM and Galambos JT. "Amino acid therapy of alcoholic hepatitis". The Lancet (1980): 1276-1277.

18. Fischer JE. "Amino acids in hepatic comma”. Digestive Diseases and Sciences 27 (1982): 97-102.

19. Herlong HF and Diehl AM. "Branched-chain amino acids in hepatic encephalopathy". amino acids metabolism and medical applications (eds., George L. Blackburn; John, P.; Grant and Vernon R. Young). John Wright. PSG Inc, 542 Great Road, Littleton, Massachusetts 01460, USA (1983).

20. Toback FG., et al. "Amino acid-mediated stimulation of renal phospholipid biosynthesis after acute tubular necrosis". Kidney International 15 (1979): 542-547.

21. Kopple JD., et al. "Nutritional status of patients with different levels of chronic renal insufficiency". Kidney International 36.S27 (1989): S184-S194. 
22. Bali NP and Singh Balveer. "Protective role of L-lysine amino acid in toxicity of chromium in fish". Biosphere 6.1 (1994): 1924.

23. Singh Balveer. "Biopathology of a siluroid food fish exposed to stress due to chromium with special reference to the role of L-lysine amino acid". Thesis submitted to Meerut University, Meerut, U.P., India (1995).

24. NAS: Chromium committee on biological effects of atmospheric pollutants". National Academy of Sciences, Washington D.C (1974).

25. Gray SJ and Sterling K. "The tagging of red cells and plasma proteins with radioactive chromium". Journal of Clinical Investigation 29 (1950): 1604-1613.

26. Donaldson RM and Barreras RF. "Intestinal absorption of trace quantities of chromium". Journal of Laboratory and Clinical Medicine 68 (1966): 484-493.

27. Domingo JL. "Cobalt in the environment and its toxicological implications". Reviews of Environmental Contamination and Toxicology 108 (1989): 105-132.

28. Ali Z., et al. "Toxicity and bioaccumulation of manganese and chromium in different organs of common carp (Cyprinus carpio) fish". Toxicology Reports 8 (2021): 343-348.

29. Gehan BAY., et al. "Pratective role of Vitamin-C and Thyme extract (Thymus vulgaris) on chromium induced toxicity in catfish (Clarias gariepinus)". Asian Journal of Animal and Veterinary Advances 16.1 (2021): 1-13.

30. Strick JJTWA., et al. "Toxicity of chromium (VI) in fish, with special reference to organs or weight, liver and plasma enzyme activities, blood parameters and histological alterations. In: Koeman SH and Strick JJTWA. "Sublethal effects of toxic chemical on aquatic animals, Amesterdam, New York, Oxford, Elsevier Science Publishers (1975): 31-41.

31. Masud T., et al. "Adaptive responses to very low diets: The first comparison of keto acids to essential amino acids". Kidney International 45 (1994): 1182-1192.

32. Singh Tejavath A., et al. "Impact of branched chain amino acid on muscle mass, muscle strength, physical performance, combined survival and maintenance of liver function changes in laboratory and prognostic markers on sarcopenic patients with liver cirrhosis (BCAAS study): A randomized clinical trial". Frontiers in Nutrition 8 (2021): 715795.
33. Doig GS., et al. "Intravenous amino acid therapy for kidney function in critically ill patients: A randomized controlled trial". Intensive Care Medicine 41.7 (2015): 1197-208.

34. Zager RA., et al. "Acute amino acid nephrotoxicity". Journal of Laboratory and Clinical Medicine 101 (1983): 130-140.

35. Recusen LC., et al. "Mechanism of lysine induced acute renal failure in rats". Kidney International 27 (1985): 517-522.

36. Dhami BS. "Acute high dose of L-lysine amino acid leads nephrotoxicity and hepatotoxicity in freshwater fish Clarias batrachus". Environment Conservation Journal 21.3 (2020): 143148.

\section{Assets from publication with us}

- Prompt Acknowledgement after receiving the article

- Thorough Double blinded peer review

- Rapid Publication

- Issue of Publication Certificate

- High visibility of your Published work

Website: www.actascientific.com/

Submit Article: www.actascientific.com/submission.php

Email us: editor@actascientific.com

Contact us: +919182824667 